\title{
Teen Pregnancy in Durango Mexico: A Cultural Perspective
}

\author{
Rebeca Treviño-Montemayor \\ Psychology and Human Communication Department, Juarez State University of Durango, Durango, Mexico \\ Email: rtr2706@yahoo.com.mx
}

How to cite this paper: Treviño-Montemayor, R. (2018). Teen Pregnancy in Durango Mexico: A Cultural Perspective. Psychology, 9, 2384-2395.

https://doi.org/10.4236/psych.2018.910136

Received: August 2, 2018

Accepted: September 14, 2018

Published: September 17, 2018

Copyright (C) 2018 by author and Scientific Research Publishing Inc. This work is licensed under the Creative Commons Attribution International License (CC BY 4.0).

http://creativecommons.org/licenses/by/4.0/

\begin{abstract}
The present research attempts to draw an in-depth understanding of adolescents' conceptualizations of romantic and gender relationships, which attempted to understand how stereotyped behavior impacts on young girls' pregnancy decisions. It is a qualitative study that considers own adolescents' view of marriage and motherhood as an important part of their future life. Qualitative methodology and ethnographic and hermeneutic tools were used to enlighten hidden elements from which statistics and quantitative studies do not show concerning teenage pregnancy, a very important problem in the North West Region of Mexico, particularly in Durango. A comprehensive analysis listening to adolescents themselves can help to reduce adolescent's fertility and pregnancy rates. Sexual education is officially included in Mexican basic schools; however, it has focused in biological and hygiene issues; the study highlighted the important needs girls and boys have to know about sexual and romantic interaction as a very basic part of sexual education. It was not only about instructing in the use of contraceptive methods but in a real and effective education understanding the cultural context where early pregnancy happens.
\end{abstract}

\section{Keywords}

Culture, Gender Stereotypes, Adolescents, Comprehension

\section{Introduction}

As one of the most important social problems Mexico faces nowadays; adolescents' pregnancy maybe represents the most difficult challenge (OECD, 2012; ENPEA, 2015). Among the countries of the Organization for Economic Co-Operation and Development, which includes a number of developing countries (OECD, 2012: p. 84), Mexico has the highest birth rate (64.2 per 1000 
births) among adolescents between 15 and 19 above Chile Costa Rica Uruguay and Peru (UNFPA, 2013; PAHO, 2017) nations of the same level of development (OECD, 2012: p. 84). National statistics concerning teenage pregnancy have some difficulties because the sources are not comparable in terms of the methodology employed (Ehrenfeld, 2017); however, all agree that between 2009 and 2014 fertility adolescents' rate increases 10 percent (ENADID, 2009; Mier y Terán, 2011).

Most research in Mexico likewise in Latin America emphasizes poverty and social marginalization as causes and effects of teen pregnancy (García Hernández, 2014; Herrera, 2017; Azevedo et al., 2012). In fact, some research correlates teen pregnancy and poverty as a vicious circle (García Hernández, 2014; De Jesus-Reyes \& González, 2014; ENPEA, 2015). Additional evidence suggests that becoming pregnant during adolescence has negative effects on the opportunities of the mother, particularly decreasing years of schooling and poorer labor market outcomes for women (Arceo-Gomez \& Campos-Vazquez, 2014). Correlation between poverty and teen pregnancy seems to be the rule but correlation does not mean causation. Durango, Coahuila and Chihuahua states, in North West Mexico are not the poorest region in Mexico; but nonetheless these states have the highest adolescent fertility rate (ENADID, 2009; ENSANUT, 2012).

Under this scenario, the Mexican government reaction launched in 2015 the National Strategy to Prevent Teen Pregnancies in Adolescents (ENPEA). This document shapes policies to prevent and face the problem from different aspects: education, health and job training which are essential. In fact, this strategy seeks to reduce in 50 percent of the Specific Fertility Rate in women 15 - 19 years old, it also pursuits to prevent school failure by scholarships, to increase health access, to intensify contraceptive use, reduce gender violence and men and women inequality.

Research in Durango emphasizes the clinical, epidemiological, and medical views (Salvador et al., 2000; Salvador-Moysén et al., 2005; Juarez et al., 2010). These studies prioritize the association between health and adolescence; however, there is a socio-cultural perspective necessary to be considered in order to get a closer comprehension of the complexity of the early pregnancies occurrence. One of them is cultural gender stereotypes which are not reviewed in sexual courses and can be linked to early pregnancy and marriage decision neither it is itself visible as a pattern to be followed in adolescent's identity and personality built. Social psychologists think that the stereotype is one part of an individual's social knowledge and a part of the socialization process (Crespi, 2003). The culture of an individual influences stereotypes through information that is received from indirect sources such as parents, peers, teachers, political and religious leaders, and the mass media. Hence, cultural and social stereotypes are an outstanding factor to understand adolescents' first gender interaction and pregnancy decision.

Therefore, adolescent pregnancies are the consequence of an interlocking set 
of factors such as widespread poverty, families' and social acceptance as a part of being women. Also, a Mexican young woman stereotyped role is to be a mother. Pregnancies are sometimes the result of a deliberate choice following gender cultural tradition. There are at least two important questions: Are early pregnancies and child marriage a deliberate and free girls' choice or Are pregnancies the result of an absence of different choices and better circumstances for girls?

The aim of this study was to listen and understand the meaning of gender stereotypes that Mexican adolescents have and how these influence and dictate their subjective beliefs, attitudes and values in gender interaction. The research picked up adolescents' dialogues and non-verbal communication to get a closer understanding of early pregnancies decision even when it represents a risk not only because of socio-economic conditions but emotional and cultural environments.

\section{Problem Statement and Methodology}

The present study conducted a qualitative analysis which, given the complexity of this phenomenon, might add depth to quantitative studies and may enlighten other important aspects, particularly, concerning how young boys and girls face their own adult life incorporation. Information was obtained by observation, focus group discussions, and semi-structured interviews, which provided a whole comprehensive phenomenon view. To recognize the cultural view of adolescents may help to integrate a complete strategy conjointly to health information about sexual and pregnancy risks. Although this work was not large enough to include non-urban adolescents, its findings will be useful to discuss and assess Government strategies to control adolescent fertility rate.

Qualitative analysis implied close observation, listening, and interpretation of official practices through speeches and symbolic behaviors. Through the use of qualitative methods, it looks at teenage pregnancy from the adolescents' perspective and shows the importance of different actors in their fertility decision. "It also identifies contradictory cultural norms that recriminate teenage sexual activity while seeing motherhood as a ritual of passage to adulthood" (Santos, 2012: p. 655).

The qualitative method includes ethnographic and hermeneutic tools; it allows to observe and to interrelate participants-researchers (Dietz \& Alvarez, 2014). It also admits and requires careful interpretation. Qualitative studies look to understand the meaning built between two subjects: participants (in their environment and researcher). The researcher must have analytic categories derived from theory to contrast participants' narration. The use of hermeneutic tools in qualitative studies means that the narrative construction is an interpretation that encompasses the description of the events, the analysis of already thought-out theory's categories, and the unexpected sensations that come out between participants and researcher during the research process, all these experiences in common mix together to shape the reality perception. The challenge in this kind 
of analysis is to identify all the things that usually are unnoticed because they are often disguised by our own cultural background, often seen as "natural". "Ethnography builds the narration-interpretation from the narrations and lived situations by the research subjects, and the shared experiences emerging necessarily when both universes (researcher and participants) combined and mixed together" (Dietz \& Alvarez, 2014: p. 60).

The hypothesis that teenage pregnancy is frequently unwanted or unplanned suggests that one of the causes may be the insufficiency or inadequacy of family planning programs (Santos, 2012: p. 656; Azevedo et al., 2012: p. 15).

However young girls' sexual activity and the pregnancy decision are processes affected by the local social situation, the household environment and the effective options available for teenage girls to determine their life plan. Sex education should include socio-cultural factors. It is not enough for sex education courses in basic schools to include discussions of anatomy, health, and contraception to help them to avoid unintended pregnancy or disease. It is important to provide children and adolescents with a complete panorama of gender interaction and romantic relationships.

\section{Theoretical Basis and Analytic Categories}

Recent researches about sexuality and adolescence have been focused on retrieving the gender category (Lamas, 1999; Stern, 2007). Gender category is understood as the socio-cultural attributions as well as the masculine and feminine differences. Gender identities are also considered the basis to understand two important categories in social science, normality and control (Foucault, 2008). Gender and identity are not cannot separate concepts, especially in the construction of personality in young people, hence sexual education plays an important role. A question should be done for this purpose, how many culture standards and morals are taken as ethic ideals in one generation and passed to the next one (Lamas, 1998). Consequently, there is another important category: gender stereotypes (Stern, 2007). Traditionally, men are supposed to be breadwinners; women belong home: cooking, cleaning, and caring for children. Women are meant to be submissive and weak. Gender stereotypes such as these prevail nowadays in the majority in Durango.

Therefore, maternity and building a family is seen by Mexican women as the most important and beautiful goal. This message is given by family, school teachers, political and religious leaders and mass media, further explicit traditional gender stereotyped roles and hidden messages are transferred from the old generation to the young one: Men expect to be active, reckless, insensitive, extroverted, unemotional, while women are expected to be tender, sensitive, emotional, passive and careful. Both genders are supposed not to engage in premarital sex, be respectful to family and religion. The hidden message in mass media and popular music for boys is to be aggressive, be "macho", seduce and control women; while for girls the message in these media is to be mother pictured as 
the most beautiful mission no matter what circumstances are. As a result, girls want to have children and build a family and boys want a woman to build and take care of the family for them in which he is the boss. Both boys and girls are trapped in this traditional discourse reinforced by religion and social morality, However, in this trap, girls are in worse conditions, cultural discourses condemn them to get pregnant but, at the same time, it encourages them to preserve the only status where women are visible, and sexual activity is valid: maternity.

Thus, analytic categories to build interpretation were:

1) Gender stereotypes transferred into sexual courses.

2) Hidden traditional and cultural messages boys' and girls' have taken to conceive their own gender and subjective personality.

3) Unspoken gender behavior assumed as "natural".

4) Family, school, and mass media role in gender identity and personality development in young boys and girls.

5) Adolescents' romantic interaction and sexual cautions among teenagers.

6) Sexual courses as insufficient to answer all adolescents' doubts and real interest.

\section{Participants and Organization}

The research was developed through ten sex education workshops, five focus group discussion and two semi-structured interviews. Workshops were presented to all students in classrooms, and were conducted to all: 122 students, fifty-four male and sixty-eight female students at four Durango city public junior high schools. The schools were those who accepted research intervention and one of them have had two pregnant students, (13 and 14 aged) in that school teachers were concerned and wanted to prevent more pregnancies, asked for additional help. The other three schools have not reported pregnancies but were worried about emotional problems students have reported and were open to this kind of intervention because they considered sex education as an important issue to care about. Hence, the research was planned as a psychological intervention to prevent anxiety around romantic relationships, gender expectation during dating, sexual care and beliefs about early pregnancy. For ethical reasons, and since all junior high students were minors, we asked the informed consent of their parents. Subject requirement involved a previous written official letter to the school principal, social science teacher and parents looking for authorization to researcher's interaction to teenagers through ten sexual education modules. Teachers and parents were informed about the visual material, psychological dynamics and information given to adolescents, all of them authorized by current educational programs.

Workshops topics were conceived assuming that the sexual topic had already been taught in the formal education courses since elementary education, this topic is included in public and obligatory programs of all Mexican schools since eighty decade (Robles-Espinoza, 2015). Nevertheless research on sexual educa- 
tion in Mexico has shown that teachers focused on biological and hygienic education, due to cultural values, attitudes and behaviors to sexuality, which is often a taboo subject shared by educators as parents as well (Rodríguez, 2016).

During the workshops, students got the confidence of the moderator and it made possible to have volunteers for closer discussion throughout four focus group discussion and two semi-structured interviews. These focus group discussion and interviews were carried out at school both interviewed students were volunteer girls, all boys refused to have this closer conversation. The workshops were organized like an ordinary class, but the topics were unusual for them. For instance, "how to get a date with the girl or boy I like?" or "What makes me a man or a woman?" "What to do to avoid violence?" and "How to refuse sexual interaction when I am not sure?" The most active and participative students were invited to the focus discussion groups. There was four focus group 5 or 6 participants each one; two of them were organized gender separated, one only for girls, and the other one only for boys. The focus groups split was made because teens asked for it because the wanted to feel free to talk about their doubts. All focus discussion interviews were conducted from February to June 2017 during the school day. Duration of interviews was of 50 minutes. Author role was to moderate and to maintain discussion focused on issues previously subjected in sexual education classes given to the complete students' group. Sexual classes to all participants were scheduled the previous semester.

All conversations were recorded in a voice diary and also in a binnacle notebook to highlight the most important phrases and more significant behavior.

During all research, the author was the moderator and was helped by her two psychology students to pick up behavior observation in the classroom, as well as in focus discussion group sessions. Semi-structured interviews were conducted by the author too.

\section{Results and Discussion}

During the first workshop session adolescents said they already know what we were going to talk: "contraceptive methods and biological changes in adolescence". "This is been taught to us since elementary school". They were used to education sexual classes as one more in their classes; in fact, school is the main place where they get sexual information (87.5\%). When they have been asked about who has given them the essential information, $73 \%$ indicated that teachers were who provided the best and clearest information about sex and gender relationships; $98 \%$ of participants said they already had information about contraception and sexually transmitted diseases. However, when sex education classes were conducted, they focused on sexually transmitted diseases questions (STD). None of the participants, 14 average, had engaged in sexual activity yet, however, 18 girls (26\%) had started dating, and wanted to know how to refuse sex filtering and sexual harassment. They appointed that romantic relationship is important for them but they do not want to engage in sexual intercourse as boys believe. 
They have heard at home since they were kids: be respectful to yourself, make yourself to be respected by others (Darse a respetar in Spanish). This is almost an order Mexican girls' received once they become adolescent, specifically when the first menstruation appears. This means not to have premarital sex. The idea if they have sex, any circumstance, sometimes even rape or incest is because the girl did not make herself to be respected. This command is very clear for girls and boys, especially in the age of our participants. They know about it, but not all of them agree. When they realized sex education classes were going to be about this kind of dialogue, and they acknowledged we were talking beyond biological sex they showed more interest. For instance, when they played role gender games, they identified inequitable gender attributes: A girl commented: I don't like menstruation, I don't like to make house cleaning, I don't like the fact I can't go out, they (the boys) like everything of being men, it's not fair! Indeed gender roles may not be fair maybe biology does not seem fair either. This was the conclusion teens' got of that discussion session.

Majority of teens showed enthusiasm about sex education through games and dynamics, when proper intervention has started and girls showed more interest, probably because it was the first time they would be able to talk about the topic in a dynamic class performance; even though they had claimed to know enough about sex, issues including information about dating and romantic behavior were of their interest. In other sessions, topics about violence during dating and when to be ready for sexual activity, both very remarkable, almost all groups-girls and boys-were very curious about a correct age for beginning sexual activity. Girls were, usually very inquisitive about how to maintain a romantic relationship without implicating sex.

In general, in workshops sessions teenagers very enthusiastic, games and dynamics made them forget other demanding classes. When they felt more comfortable the focus discussion groups were joined encouraging the quiet ones, but they deny; so we achieved to make four different discussions sessions. The best information came from the gender-separated groups. For example, men group discussion about what does being a man means? The following conversation is a good example of boys' concept:

Question: What does being a man mean to you?

Answer. Well, you know, to do manly stuff, like smoking, drinking, going out with friends, girlfriends especially, and be able to be close to them.

-Lay with them (said another boy)

Q: Have you done all that stuff?

A: I did, with my older brothers, I go dancing parties I can already drink beers ... even smoke.

Q: But ... have you had sex there?

A: No not yet, when I turn 15, I'm almost there, it is been said that when you are 15 you can do it... You're a man then ... hahaha.

Boys usually were shier than girls about manly behavior during sex education 
classes, but among other boys, they looked more extroverted. To boys, the idea of sexual intercourse is conceived as a masculinity achievement as well as alcohol and tobacco consumption. Although, when they were asked about if women are able to do the same at theirs fifteen they replied: some of them do it, maybe I would like as a girlfriend someone like that, so I could have sex without getting married. The gender stereotype is strongly rooted, yet these boys were in sex education workshop and took place in the gender role dynamic where they could recognize the advantages and disadvantages of being men and women when they among other boys, they wanted to show off his masculinity.

However, when we asked the female group: What does it mean to be a woman to you? They commented: To be a woman is to have your period, you can get pregnant then, so you must take care, boys behave like dogs, everything is sex to them, and they do know nothing. Thanks to you this talking, let see if they learn how to respect a woman. Other girl said: To be a woman is to reach your goals by getting married, having children, having a family.

Pregnancy and motherhood are strongly linked with the female subjectivity. When they were asked what would happen if they got pregnant at this moment they replied, I suppose that my family would be there supporting me, I am not so sure though I have not questioned them about it openly, think they would help me, maybe they would be mad at first but finally they would be there for me.

One of the observers a 19 years old psychology female student, the researcher's assistant, acknowledged to have learned a lot about inequitable gender roles, she mentioned being scared she had not noticed all these inequities. She was pregnant at the moment the research was conducted and she needed to justify to participants her pregnancy had happened because she was married. It is interesting to notice how marriage plays a legitimate role for maternity; because female participants' expressed on the arrival of assistant's baby, one girl pointed out happiness for coming baby, it doesn't matter if you're not married the important thing is to have a baby, it is a blessing. Both of these women's experiences are compensatory and dignify the censured sex practice, it seems that teens assumed this by symbolic messages as the young observer indicated in an informal dialogue with them.

Teens learn about sex in school, with friends, or the internet. But stereotyped behavior is transferred by family, mass media and religious leaders. Stereotypes are not explicit they are the natural way of being. Neither is sex or the relation between love and sex spoken at home. Rather, it is assumed that sex for women starts at marriage, and for men, starts as soon as they are ready. Adolescents used to have sex education classes at school but it is not enough to guide them to social healthy gender interaction. They have mentioned that they do not know how to start dating or how to get in a romantic relation, or even or what to fall in love is and they can't ask parents that is not a conversation for home, so they appeal to friends, mass media, and internet. A girl said: it is good you came and talk to talk about it. I would like my parents would listen to what you just told 
us. Dialogues and conversations about sex and romantic relations in home remain in the dark but it is expressed by hidden messages well understood by children and adolescents. Messages like you must act like a lady, so you can marry well; is something teen girls repeat constantly. Motherhood is also thought of as an extraordinary event. They repeat it is the most beautiful thing could happen to you, even teachers in the sex education class have shown us the wonders of conception and pregnancy. This kind of education operates in adolescence mind as an incentive to think motherhood as a possibility and as not so difficult thing, here at the school two girls had to stop studying to have their baby, but you can ... you can always overcome any situation, yes your child gives you the necessary strength.

Pregnancy and teen childbearing are conceived as a possibility in young women mentality as most important it is seen as an objective. Although they mentioned wanting to study and have professional careers, first, they indicated wanting to build a family. As they grow up, these teenagers have faced contradictory feelings, Young girls feel that to be a mother is almost imperative if they want a successful life, but they know woman's education is important nowadays. For them, pre-marital sex is accepted only if the pregnancy is the consequence.

Meanwhile, sexuality is repressed as a loving expression among boys. They are usually hermetic and their participation was always more difficult. They showed resistance to sincere talk about sex as a part of love, although between jokes and laughs they expressed some kind of interest in love feelings. This topic may be controversial for boys, since they may no felt free to acknowledge and show them as sensible persons in front of other boys, if they disclosed their opinion an love or other feelings, their masculinity may be threatened, and even their comments could be used for further jokes and bullying behavior from their peers. There were some exceptions, during interviews some of them actually allowed themselves not to show off their male stereotype, for example, they were interested in knowing about how to talk and date girls. However, during a group session, a boy was confident to express his adverse attitude towards the topics commented on opinion and thoughts. He said: The more you talk about sex, the more we want to do it, it is better for us you not come to talk about it. The boy's refusal to face the adult world from the discussion and knowledge point of view may indicate his discomfort on the discussed topic because it had confronted the traditional idea that sex must remain in the silence and intimate world where is usually placed in a conservative and Catholic society, the open talk confronts that tradition.

\section{Conclusion}

Little research has been done in Mexico assessing teenage pregnancy by working directly with subjects, in their own environment and collecting first-hand accounts of their experience and social context (Ehrenfeld, 2017). This study presents an initial effort to get closer to adolescents' world, their complexity and 
they are over controlled and sexually restrained atmosphere. The research tried to understand how sex is important to build an individual identity and personality. Sexuality is a complex, diverse and intimate, inaccessible and elusive universe for most adolescents, who are experiencing one of the most remarkable stages in human life. Many biological and emotional phenomena occur in each individual during these years. Teenage years define the sexual identity and the personality of the future adult; teens have expressed their desire to integrate as equal in their society but at the same time want to reaffirm his or her singularity. Education is the only tool teens have to be prepared for adult life. But also, education is the only way the young generation has to overcome errors and mistakes inherited by the older one. Not all legacies are to be kept. Gender stereotypes and inequality are to be prioritized.

Through an integral and complete sexual education, the young generation can see unfair stereotypes for men and women and how they affect the whole society. To improve and enlarge sexual education in Durango is essential to prevent early pregnancies, but likewise, it is imperative for boys and girls, since very early age, to understand that there are many ways of being woman and man beyond cultural stereotypes.

The present essay described how limited sexual education is mainly because it rarely includes real teens' interest like pre-marital sexual intercourses and how they can be negotiated, particularly by women. Women commonly assumed a subordinate role during sexual and dating practice. Young girls grow up thinking that females worth keeping their virginity and pursuing marriage and motherhood. Meanwhile, young boys grow up taking male domination as natural and assuming that pre-marital sexual intercourses are possible and socially accepted. Family's role and culture play an important part in these mentioned double standards (Stern, 2007; Amuchástegui, 1998).

Romantic interaction and sexual flirting in adolescence are clearly influenced by gender stereotypes learned in the family and first socialization groups. Children and teenagers learn more from explicit behavior, they structure their personality and subjective aspiration around these cultural stereotyped transferred by family and reinforced by all kind of media communication. Discourses and meta-speeches are taken by young minds and make up for their behavior and values. Thus, it is important to consider spread and improve sexual education courses including emotional and cultural manners to face a more equitable society. In the conducted workshop adolescents realized that women commonly face a subordinate role in all life fields, at home, at work, and during a romantic interaction. Pregnancy is a real possibility for young girls of personal to young girls' self-realization; even though they know childbearing will limit their education and job opportunities, they do not seem to avoid it. In the young women's imaginary, motherhood is associated with the main female identity attribute. Pregnancy and childbearing are also associated, at least in teens' mind, as a kind of set them free from family's rules, especially all relating with sexual life. 
This study presented the first approach of understanding how teens think about sex, gender relationships, dating, family and social expectations. Their own voice has listened. It is important to mention how adult's sex opinion has been passed on by sex education courses. We suggest further research should include other social and cultural factors, especially those related to conservatism in Durango's society and how much the traditional is influencing future society.

\section{Acknowledgements}

I would like to acknowledge the valuable participation of the psychology students to Faptych/Universidad Juarez del Estado de Durango enrolled in social integration class, their observation reports were very useful in this research.

A very special acknowledgment and thank the important help in translating and language help to Silvana Pacheco Treviño at the University of Nottingham, without her language assistance this paper would not be possible.

\section{Conflicts of Interest}

The author declares no conflicts of interest regarding the publication of this paper.

\section{References}

Amuchástegui, A. (1998). Saber o no saber sobre sexo: Los dilemas de la actividad sexual femenina para jóvenes mexicanos.

Arceo-Gomez, E. O., \& Campos-Vazquez, R. (2014). Teenage Pregnancy in Mexico: Evolution and Consequences. Latin American Journal of Economics, 51, 109-146.

Azevedo, J. P., Favara, M., Haddock, S. E., Lopez-Calva, L. F., Muller, M., \& Perova, E. (2012). Teenage Pregnancy and Opportunities in Latin America and the Caribbean: On Teenage Fertility Decisions, Poverty and Economic Achievement. Washington DC: World Bank.

Crespi, I. (2003). Gender Socialization within the Family: A Study on Adolescents and Their Parents in Great Britain Paper for BHPS. Socialisation as the Way to Gender Roles-Semantic Scholar.

De Jesus-Reyes, D., \& González, E. (2014). Elementos teóricos para el análisis del emba razo adolescente. Sexualidad, Salud y Sociedad-Revista Latinoamericana, 17, 98-123.

Dietz, G., \& Alvarez, A. (2014). Reflexividad, interpretación y colaboración en etnografía, un ejemplo desde la educación. In C. O. Bazán (Ed.), La etnografía y el trabajo de campo en las ciencias sociales (pp. 55-89). Universidad Nacional Autónoma de México/Instituo de Investigaciones Antropológicas.

Ehrenfeld, L. N. (2017). Pregnancy in Adolescents in Mexico, Data versus Social Panic? Global Journal of Reproductive Medicine, 1, Article ID: 555562.

ENADID (2009). Encuesta Nacional de la Dinámica Demográfica. México: Int. Nal de Geografía y estadística.

ENPEA (2015). Estrategia Nacional de Prevención del embarazo adolescente. México: Secretaría de Gobernación,.

ENSANUT (2012). Encuesta Nacional de Salud y Nutrición. México: Int. Nal de Geografía y estadística. 
Foucault, M. (2008). Seguridad, territorio y población. Madrid: Akal.

García Hernández, G. E. (2014). Embarazo adolescente y pobreza, una relación compleja. Iztapalapa, Revista de Ciencias Sociales y Humanidades, No. 77, 13-53.

Herrera, C. (2017). Encrucijadas de la pobreza y el embarazo temprano en México. Revista interdisciplinaria de estudios de género de El Colegio de México, 3, 211-216. http://www.scielo.org.mx/scielo.php?script=sci_arttext\&pid=S2395-9185201700020021 $1 \& \operatorname{lng}=\mathrm{es} \& \ln \mathrm{ln}=\mathrm{e}$

Juarez, F., Palma, J. L., Singh, S., \& Bankole, A. (2010). Las Necesidades de Salud Sexual y Reproductiva de las Adolescentes en Mexico: Retos y Oportunidades. New York: Guttmacher Institut.

Lamas, M. (1998). La violencia del sexismo. En El mundo de la violencia. Adolfo Sánchez Vázquez. México: Facultad de Filosofía y Letras, UNAM, Fondo de Cultura Económica.

Lamas, M. (1999). Usos, dificultades y posibilidades de la categoría género. Papeles de Población, 2, 147-178.

Mier y Terán, M. (2011). La fecundidad en México en las últimas dos décadas. Un análisis de la información censal. CoyunturaDemográfica, 1, 57-61.

OECD (2012). Better Policies Series. Mexico Better Policies for Inclusive Development. http://www.oecd.org/mexico

PAHO (2017). Pan American Health Organization. https://www.paho.org/salud-en-las-americas-2017/?tag=adolescent

Robles-Espinoza, G. (2015). La educación sexual en México. Revista electrónica de medicina, salud y sociedad, 6, 1-6.

http://cienciasdelasaluduv.com/revistas/index.php/mss/article/view/193

Rodríguez, G. (2016). Treinta años de educación sexual en México. In M. L. Mícher (Ed.), Población, desarrollo y salud sexual y reproductiva (pp. 13-28). México: Grupo Parlamentario del PRD Cámara de Diputados Congreso de la Unión LIX Legislatura. https://archivos.juridicas.unam.mx/www/bjv/libros/7/3483/3.pdf

Salvador, M. J., Martínez, L. Y., Lechuga, Q. A. M., Ruiz, A. R., \& Terrones, G. A. (2000). Situación psicosocial de las adolescentes y toxemias del embarazo. Salud Pública de México, 42, 99-105.

Salvador-Moysén, J., Martínez-López, Y., Lechuga-Quiñones, A., \& Terrones-González, A. (2005). Hipertensión inducida por el embarazo en adolescentes: un estudio multicéntrico. Rev Ansiedad y Estress, 11, 181-188.

Santos, K. A. (2012). Teenage Pregnancy Contextualized: Understanding Reproductive Intentions in a Brazilian Shantytown. CadernosdeSaúdePública, 28, 655-664.

Stern, C. (2007). Estereotipos de género, relaciones sexuales y embarazo adolescente en las vidas de jóvenes de diferentes contextos socioculturales. México Estudios So ciológicos, $X X V, 105-129$.

UNFPA (2013). Motherhood in Childhood Facing the Challenge of Adolescent Pregnancy. New York, NY: The United Nations Population Fund. 